\title{
Investigating Suspended-Sediment Transport in a Shallow Lake Using a Three-Dimensional Model
}

\author{
Hong-Ming Liu ${ }^{1}$, Wen-Cheng Liu ${ }^{1,}{ }^{*}$, Chih-Yu Chiu ${ }^{2}$ \\ 1 Department of Civil and Dis a ster Prevention Engineering, Na tional United University, Mia oli 36063 \\ Taiwan; wcliu@nuu.edu.tw; dslhmd@gmail.com \\ 2 Research Center for Biodiversity, Aca demia Sinica, Taipei11529 Taiwan; bochiu@sinica.edu.tw \\ * Correspondence: wcliu@nuu.edu.tw; Tel.: +886-37-382357
}

\begin{abstract}
A three-dimensional, unstructured grid, hydrodynamic and suspended-sediment transport model (i.e., SELFE-SED) was developed to simulate temporal and spatial variations of suspended sediment and was applied to the subtropical subalpine Tsuei-Feng Lake (TFL) of Taiwan. The model was validated with measured water level and suspended-sediment concentration in 2009, 2010, and 2011. The overall model simulation results are in quantitative agreement $w$ ith the observational data. The validated model $w$ as then applied to explore the most important parameter that affects the suspended-sediment concentration and to investigate the effect of wind stress on the mean current and suspended-sediment distribution in this shallow lake. Modeling results of sensitivity analysis reveal that the settling velocity is a crucial parameter and erosion rate is less important in the suspended-sediment transport model. Remarkable lake circulation was found based on the strength of wind speed and wind direction. Strong wind would result in higher mean current in the top layer and suspended-sediment distribution in the top and bottom layers. This study demonstrated that the wind stress played a significant influence on mean circulation and suspended-sediment transport in a shallow lake.
\end{abstract}

Keywords: Suspended sediment, Hydrodynamics, Numerical model, SELFE-SED, Wind-driven current, Tsuei-Feng Lake.

\section{Introduction}

Sediment has been identified as one of the important nonpoint source pollutants [1]. Sediment-water interactions in shallow lakes may become enormously important $w$ ith time, since bed sediments constituent the ultimate repository for nutrients and contaminants, and fine particles and nutrients in the sediment bed may repeatedly be recycled [2,3]. Nutrient-rich sediment layers in the lakes participate in chemical and biological processes and exchange mass with in the water column. The sediment layers affect the nutrient cycles via the diffusive fluxes of nutrients from sediment and via sediment resuspension [4-6]. The resuspension of toxic bottom sediments is an ecological concern, since toxic contaminants can accumulate in the biota and food web of a lake [7]. Suspended sediment can also reduce the light intensity under water and affect the growth of phytoplankton.

The dynamic processes involved in suspended-sediment transport such as flocculation, deposition, and erosion (resuspension) have been studied by many scientists [8-16]. A number of laboratory studies have improved our knowledge of the resuspension behavior of fine-grained material. How ever, transferring the results of laboratory experiments to field studies still has been problematic because of the complexities of real sediments and of natural flows.

Sediment transport models have been broadly developed and applied to investigate sediment dynamics in lakes including a one-dimensional model [17-19], a vertical two-dimensional model [20,21], a horizontal two-dimensional model [22-26], and quasi-three-dimensional [27] and three-dimensional models [28-32]. The erosion and resuspension of bottom sediment from the 
active layers is one of the major sources of the total suspended sediment in the water column [33]. To accurately simulate the suspended-sediment concentration in lakes, incorporating resuspension and deposition into the suspended-sediment transport model is essential. However, three-dimensional models are particularly appropriate in cases such as regions with complex bathymetries, the vertical gradients in water temperature and suspended-sediment concentration, and density currents in the lakes.

Recent advances in computational fluid dynamics and sediment transport model formulations enable the computation of flows and sediment fluxes in three-dimensions. However, spatial and temporal scales, and model processes must be carefully selected for a particular study to ensure that the model will solve the problem at hand and that computations can be carried out in the practical sense. In the present study, a three-dimensional, unstructured-grid hydrodynamic and suspended-sediment transport models (i.e., SELFE-SED) were developed and applied to simulate the hydrodynamics and sediment dynamics in the Tsuei-Feng Lake. The model simulation was validated against profiles of water level, and time-variation and spatial-variation suspended solids from 2009 to 2011. The validated model then was applied to explore the most sensitive parameter affecting the suspended-sediment concentration and the influence of wind stress on mean currents and sediment dynamics.

\section{Description of Study Area}

Tsuei-Feng Lake (TFL) is located between the Taiping Mountain and Dayuan Mountain in the north-central region of Taiw an (Figure 1a). The indicated altitude is 1,900 $\mathrm{m}$ above sea level. The area of the lake is approximately 20 ha. It is one of the largest mountain lakes in Taiwan. It is also the most popular focus in the Taipingshan National Forest Recreation Area.

The regulation of the water flow into TFL primarily results in extreme water level fluctuation, which severely affects the activity and succession of fauna and flora in the area. The average annual temperature is approximately $11.4^{\circ} \mathrm{C}$, and the annual precipitation is more than $3,662 \mathrm{~mm}$. TFL is subject to several typhoons in the summer and autumn each year, during which more than 1,300 $\mathrm{mm}$ of precipitation may fall on the lake. The water column is stratified from early April to October. The water column is usually completely mixed in the winter and is associated with intensive rainfall during the typhoon season. The water quality variables of $\mathrm{pH}$, dissolved oxygen, total nitrogen, and chlorophyll $a$ are in the range of $5.4 \sim 6.5,5.9 \sim 7.7 \mathrm{mg} / \mathrm{L}, 0.5 \sim 1.4 \mathrm{mg} / \mathrm{L}$, and $0.4 \sim 6$ • $\mathrm{g} / \mathrm{L}$, respectively [34]. The spatial distributions of suspended-sediment concentration on June 6 and December 11, 2010 are shown in Figure 2. These indicate that the suspended-sediment concentration is higher on December 11 (during the autumn season), while it is lower on June 6 (during early summer). The suspended-sediment concentration in the lake exhibits temporal and spatial variations. According to a sieve analysis, the bottom sediment type can be described as being betw een fine sand and silt [34].

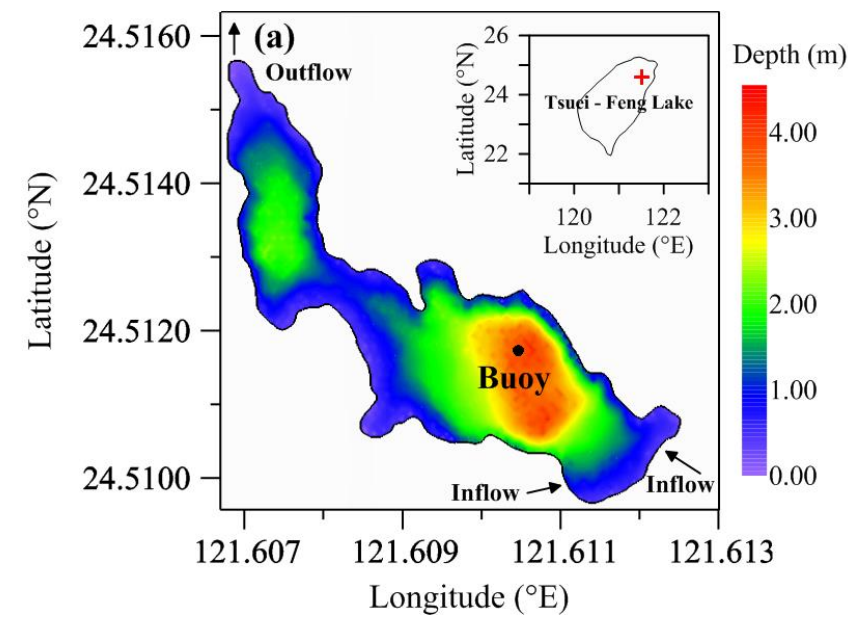




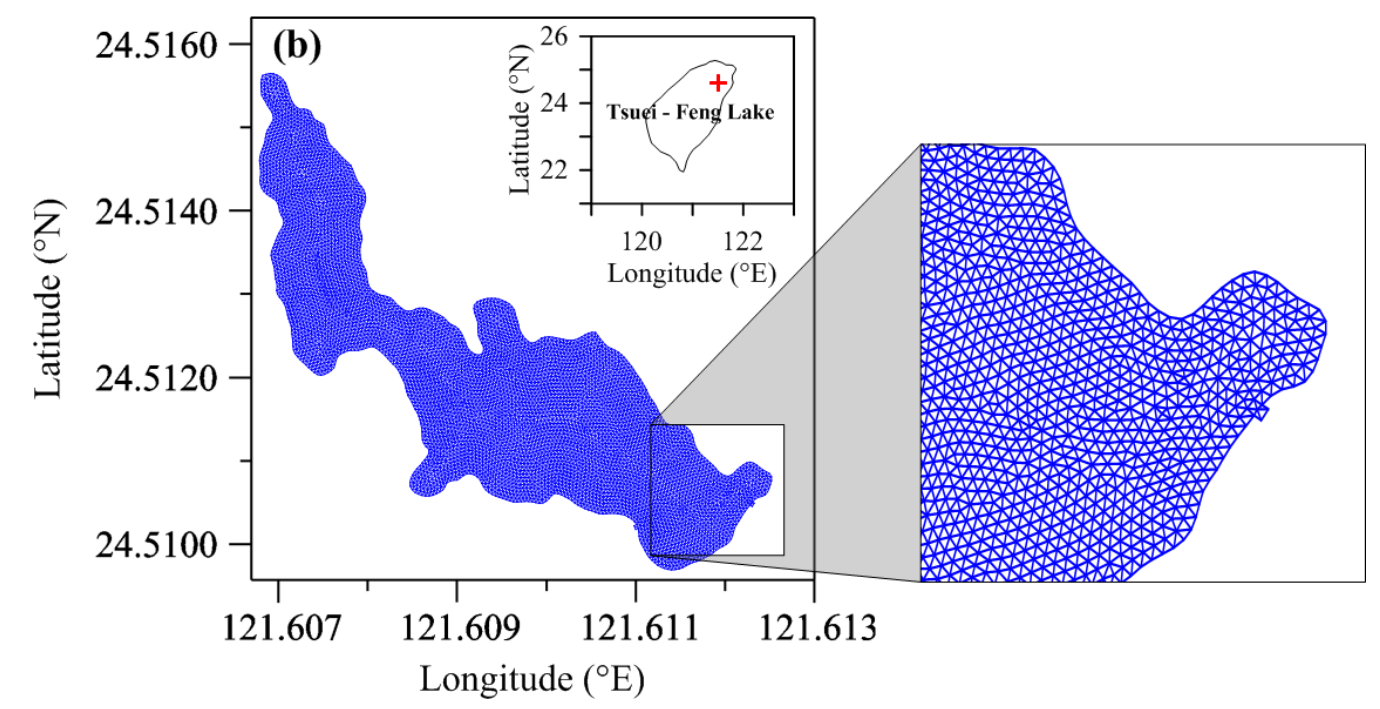

Figure 1. (a) Map of Tsuei-Feng Lake (TFL) in the north-center region of Taiwan and (b) horizontal grid of TFL for three-dimensional hydrodynamic and suspended-sediment transport model. The grid size is a pproximately $5 \mathrm{~m}$.
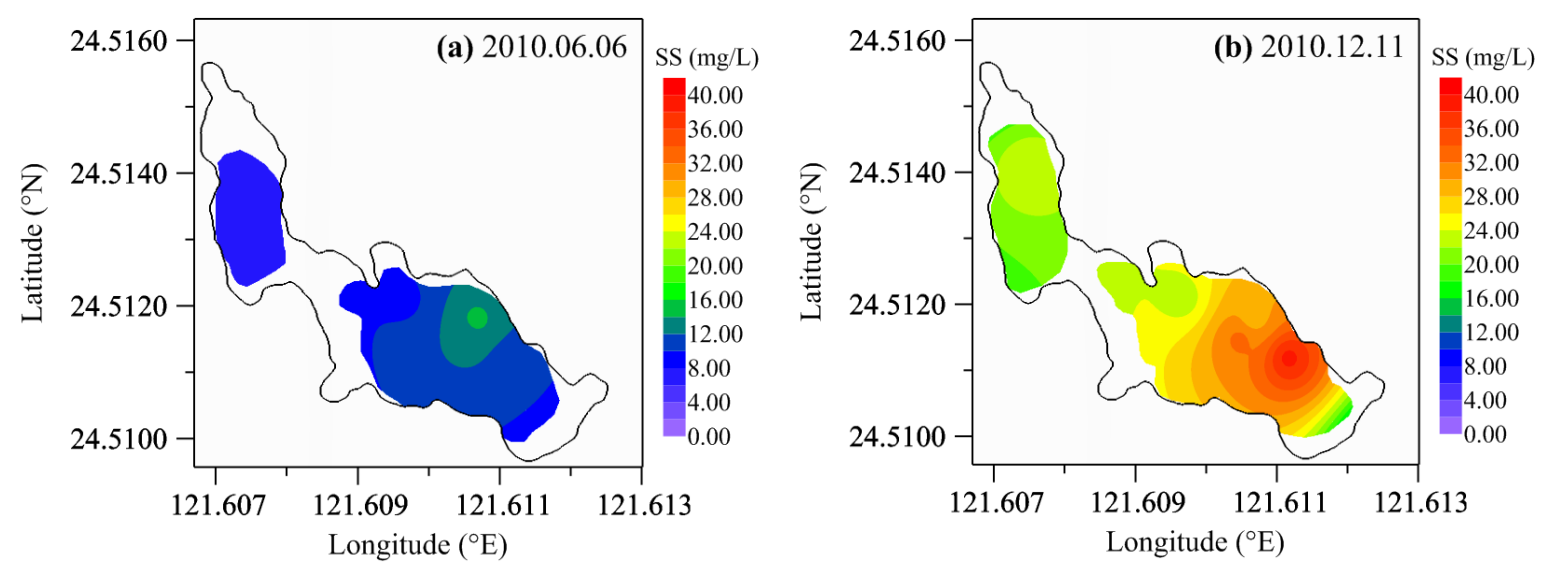

Figure 2. The spatial distribution of suspended-sediment concentration on (a) June 6, 2010 and (b) December 11, 2010. The white color in the figure represents the dry area (no water).

\section{Materials and Methods}

\subsection{Hydrodynamic Model}

Multi-scale lake circulation modeling has become a mature field. The models used typically describe the free-surface elevation, velocities, and water temperature of various water bodies by solving the Reynolds-averaged Navier-Stokes equations which represent conservation of mass, momentum, and water temperature subject to the hydrostatic and Boussinesq approximations. The equation of state describes water density as a function of water temperature. In this study, the three-dimensional, semi-implicit Eulerian-Lagrangian finite-element model [35] was implemented to simulate the hydrodynamics and hydrothermal characteristics in the Tsuei-Feng Lake.

The SELFE model solves the governing equations using a semi-implicit finite-element/volume scheme with a key step of decoupling continuity and momentum equations via the bottom boundary. In SELFE, the horizontal domain is discretized with unstructured triangular grids. Along the vertical direction, a hybrid coordinate system consisting of the S-coordinate and Z-coordinate in the upper and deeper parts of the water column, respectively, can effectively prevent the so-called hydrostatic inconsistency issue. The model handles the advection terms in the momentum equation 
with an Eulerian-Lagrangian method, allowing larger time steps without compromising computational stability and accuracy. For the advection terms in the transport equations (i.e., water temperature), the Eulerian-Lagrangian scheme is applied. When the Eulerian-Lagrangian scheme is used, the transport equations can be efficiently solved by a finite-element method. To calculate turbulent mixing processes, SELFE uses the generic length scale (GLS) turbulence closure of Umlauf and Burchard [36], which has the advantage of encompassing most of the 2.5-equation closure $(K-\psi)$ model.

\subsection{Suspended-Sediment Transport Model}

The suspended-sediment transport model is treated in two distinct models: the advection-diffusion components are based on the SELFE transport formulation, taking advantage of its numerical characteristics, such as the option to use different methods to solve the transport equation, while the remaining terms are computed based on the sediment transport formulation of a three-dimensional hydrodynamic-eutrophication model [37].

The suspended-sediment transport model was incorporated using the hydrodynamic model as a passive tracer under the same spatial and temporal resolutions. The governing equation for the total suspended-sediment concentration is as follows:

$$
\frac{\partial C}{\partial t}+\frac{\partial(u C)}{\partial x}+\frac{\partial(v C)}{\partial y}+\frac{\partial\left[\left(w-w_{s}\right) C\right]}{\partial z}=\frac{\partial}{\partial z}\left(\kappa \frac{\partial C}{\partial z}\right)+F_{S}
$$

where $C$ denotes suspended-sediment concentration, $u, v$ and $w$ are the velocity components in the $x, y$ and $z$ directions provided by SELFE, respectively, $w_{s}$ is the settling velocity of the suspended sediment, $\kappa$ is the vertical eddy diffusivity and $F_{s}$ represents horizontal diffusion.

At the water surface, there is no net transport across the free surface, and, therefore, diffusion flux always counterbalances the settling flux and the boundary condition

$$
w_{s} C+\kappa \frac{\partial C}{\partial z}=0 \quad \text { at } z=\eta
$$

where $\eta$ is the free-surface elevation.

At the sediment bed, the net sediment flux is equal to the summation of the sediment erosion flux and the sediment deposition flux.

$$
w_{s} C+\kappa \frac{\partial C}{\partial z}=D-E \quad \text { at } z=-h
$$

The erosion term $E\left(\mathrm{kgm}^{-2} \mathrm{~s}^{-1}\right)$ is expressed according to the Partheniades [8] formulation, using the excess-bottom shear-stress concept:

$$
E= \begin{cases}M\left(\frac{\tau_{b}}{\tau_{c e}}-1\right) & \text { for } \tau_{b}>\tau_{c e} \\ 0 & \text { for } \tau_{b} \leq \tau_{c e}\end{cases}
$$

where $\tau_{b}$ is the bottom shear stress $\left(\mathrm{Nm}^{-2}\right), \tau_{c e}$ is the critical shear stress $\left(\mathrm{Nm}^{-2}\right)$ for erosion, and $\mathrm{M}$ is the erosion coefficient $\left(\mathrm{kgm}^{-2} \mathrm{~s}^{-1}\right)$.

The deposition term $D\left(\mathrm{kgm}^{-2} \mathrm{~s}^{-1}\right)$ is calculated following the Krone [9] formulation:

$$
D= \begin{cases}w_{s} C_{b}\left(1-\frac{\tau_{b}}{\tau_{c d}}\right) & \text { for } \tau_{c d}>\tau_{b} \\ 0 & \text { for } \tau_{c d} \leq \tau_{b}\end{cases}
$$

where $\tau_{c d}$ is the critical shear stress $\left(\mathrm{Nm}^{-2}\right)$ for deposition, and $C_{b}$ is the near-bed suspended-sediment concentration. For simulating the hydrodynamic properties such as density 
stratification and gravitationally driven flow, the effects of suspended-sediment concentration on density have to be considered. Water density including the suspended sediment was computed as follow s:

$$
\rho=\rho_{w}+\mathrm{C}\left(1-\frac{\rho_{w}}{\rho_{s}}\right)
$$

where $\rho_{w}$ is the water density, which is determined by the equation of state, and $\rho_{s}$ is the suspended sediment density.

\subsection{Model Implementation}

In this study, the bottom topography data in the TFL measured in 2008 were obtained from the Academia Sinica, Taiwan. The greatest depth of study area is $4.3 \mathrm{~m}$ where is close to the buoy station (Figure 1a). The unstructured model meshes for TFL consist of 11617 meshes/6058 nodes in the horizontal direction (Figure 1b). High-resolution unstructured meshes, which include a mesh size of approximately $5 \mathrm{~m}$, were used for TFL. Model simulations were conducted using ten S-levels in the vertical direction. For this model mesh, a time step ( $\Delta t=20$ seconds) was used in simulations to guarantee the numerical stability.

\subsection{Indices of Model Performance}

To evaluate the performance of the hydrodynamic and suspended-sediment concentration, two criteria were adopted to compare the predicted results and the observational data, which are the mean absolute error (MAE) and root mean square error (RMSE). MAE is the average of the absolute values of differences between the observed data and simulated values. RMSE basically specifies the overall difference in the sum of squares normalized to the number of observations. RMSE is similar to a standard error of the mean for the uncertainty of the model. These criteria are defined by the following equations:

$$
\begin{aligned}
M A E & =\frac{1}{N} \sum_{i=1}^{N}\left|\left(Y_{m}\right)_{i}-\left(Y_{o}\right)_{i}\right| \\
R M S E & =\sqrt{\frac{1}{N} \sum_{i=1}^{N}\left[\left(Y_{m}\right)_{i}-\left(Y_{o}\right)_{i}\right]^{2}}
\end{aligned}
$$

where $N$ is the total number of data points and $\left(Y_{m}\right)_{i}$ and $\left(Y_{o}\right)_{i}$ are the values the $i$ th data point, modeled and observed, respectively.

\section{Model Validation}

Simulation models are increasingly being used to solve problems and to aid in decision-making. To make sure of the model accuracy for further practical applications, the observational data is used to validate the model and to ascertain its capability for predicting water level and suspended-sediment concentration [38].

The observational data collected from November 2009 to July 2011 was used for model validation. To warm up the model, the spin-up time is specified as 15 days. The model was therefore was run from November 1, 2009 to July 31, 2011. The initial conditions for w ater level and suspended-sediment concentration are specified as $3.0 \mathrm{~m}$ and $13.0 \mathrm{mg} / \mathrm{L}$, respectively, to start running the hydrodynamic and suspended-sediment transport model.

\subsection{Water Level}

The model validation of the water level was executed with daily discharge at the inflow and outflow in the lake in addition to precipitation. Figure 3 a presents the recorded rainfall which reached $48.8 \mathrm{~mm} / \mathrm{hr}$ on October 21, 2010 when Typhoon Megi hit Taiwan. The observed water levels in the TFL from November 1, 2009 to July 31, 2011 were compared with the model prediction shown in Figure $3 \mathrm{~b}$. The MAE and RMSE values between computed and observed water surface 
elevation are $0.05 \mathrm{~m}$ and $0.15 \mathrm{~m}$, respectively. It indicates that the simulated results mimic the observed water levels. Based on the model validation of water level, the roughness height used in the hydrodynamic model was adopted to be $0.01 \mathrm{~m}$ for the model simulation.
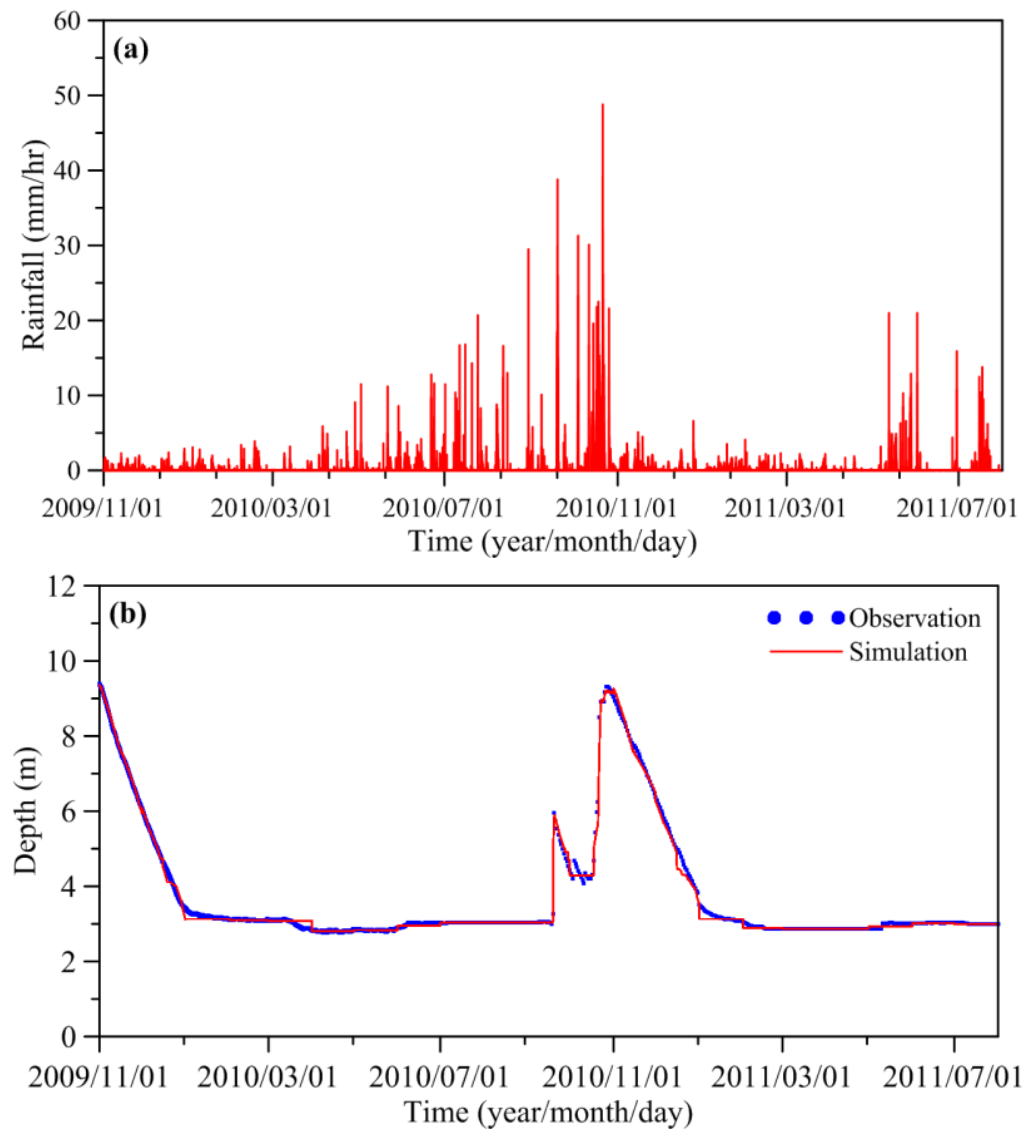

Figure 3. (a) Recorded rainfall from November 1, 2009 to July 31, 2011 and (b) comparison of water levelbetween model pre diction and observation.

\subsection{Suspended-Sediment Modeling}

Several parameters in the suspended-sediment transport model including the settling velocity $\left(w_{s}\right)$, critical stress for erosion $\left(\tau_{e c}\right)$, deposition $\left(\tau_{d c}\right)$, and empirical erosion rate $(M)$ are difficult to be determined in the lakes because they have a wide range of value to be adopted. The consolidation of the sediment bed affected by interactions with physical, biological, chemical, and the composition of sediment, is an important factor influencing these parameters [39-42]. In this study, the suspended-sediment transport model is implemented to confirm these parameters.

In order to validate the suspended-sediment concentration in the TFL, the monthly measured data collected from November 2009 to July 2011 was compared with the simulated results. The water sample was taken from different water depths to measure the concentration of suspended sediment. Concentrations of suspended sediment were determined using the drying method after filtering samples through GF/F filters [43]. The comparison of the simulated suspended-sediment concentration and the measured concentration taken as a vertical average at the buoy station is shown in Figure 4. It reveals that simulated results fairly match the measured suspended-sediment concentration. The MAE and RMSE values between the computed and measured suspended-sediment concentrations are $1.73 \mathrm{mg} / \mathrm{L}$ and $2.23 \mathrm{mg} / \mathrm{L}$, respectively.

Figure 5 presents the vertical profiles of simulated and measured suspended-sediment concentrations at the buoy station in 2010. It indicates that the model simulation results match the measured suspended-sediment concentrations in vertical profiles. Table 1 presents the statistical errors between simulated and measured suspended-sediment concentrations for each measured 
date from 2009 to 2011. It shows that the largest MAE and RMSE values are $6.41 \mathrm{mg} / \mathrm{L}$ and 9.54 mg/L, respectively, occurring on April 4, 2010.

Figure 6 illustrates the comparison of the spatial distribution of the vertically averaged suspended-sediment concentration between simulated and observed results on April 4, July 29, November 6, 2010 and January 28, 2011. It can be seen that the simulated and observed suspended-sediment concentrations in their spatial distribution are quite similar. Through the model validation, the constant values of $1.0 \times 10^{-3} \mathrm{~m} / \mathrm{s}$ for settling velocity $\left(w_{s}\right), 5.0 \times 10^{-3} \mathrm{~N} / \mathrm{m}^{2}$ for $\tau_{e c}, 5.0 \times 10^{-4} \mathrm{~N} / \mathrm{m}^{2}$ for $\tau_{d c}$, and $5.0 \times 10^{-6} \mathrm{~kg} / \mathrm{m}^{2} . S$ for $M$ were chosen for the suspended-sediment transport model.

Table 1. Statistical error between simulated and measure d suspended-se diment concentrations from November 2009 to July 2011.

\begin{tabular}{rrr}
\hline Year/Month/Date & MAE $(\mathrm{mg} / \mathrm{L})$ & RMSE $(\mathrm{mg} / \mathrm{L})$ \\
\hline $2009 / 11 / 29$ & 0.72 & 0.98 \\
$2009 / 12 / 28$ & 1.09 & 1.50 \\
$2010 / 01 / 31$ & 0.95 & 1.13 \\
$2010 / 02 / 27$ & 0.11 & 0.12 \\
$2010 / 04 / 04$ & 6.41 & 9.54 \\
$2010 / 05 / 02$ & 2.52 & 2.59 \\
$2010 / 06 / 06$ & 1.38 & 1.54 \\
$2010 / 07 / 29$ & 1.84 & 2.20 \\
$2010 / 08 / 27$ & 1.94 & 2.42 \\
$2010 / 09 / 25$ & 0.32 & 0.42 \\
$2010 / 11 / 06$ & 3.51 & 4.27 \\
$2010 / 12 / 11$ & 1.69 & 2.08 \\
$2011 / 01 / 28$ & 1.59 & 2.10 \\
$2011 / 02 / 17$ & 2.10 & 3.02 \\
$2011 / 03 / 19$ & 1.26 & 1.36 \\
$2011 / 04 / 30$ & 1.70 & 2.19 \\
$2011 / 05 / 21$ & 3.02 & 4.07 \\
$2011 / 06 / 28$ & 0.18 & 0.20 \\
$2011 / 07 / 21$ & 0.58 & 0.73 \\
\hline & &
\end{tabular}

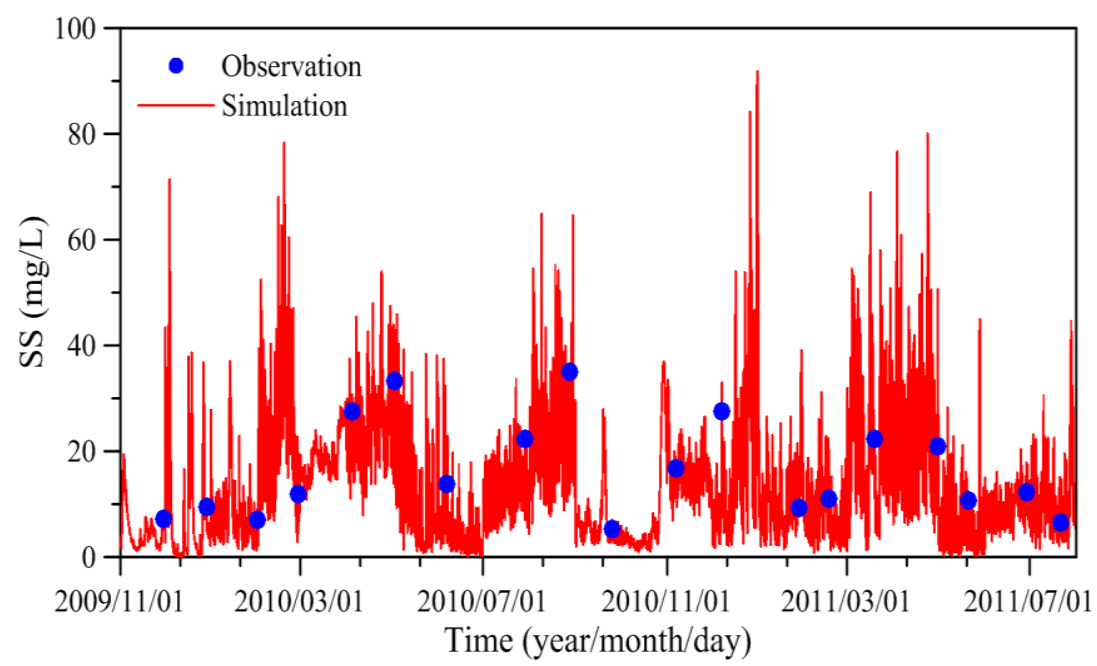


Figure 4. The comparison of suspended-sediment concentrations predicted by the model and measured at the buoy station from November 2009 to July 2011.
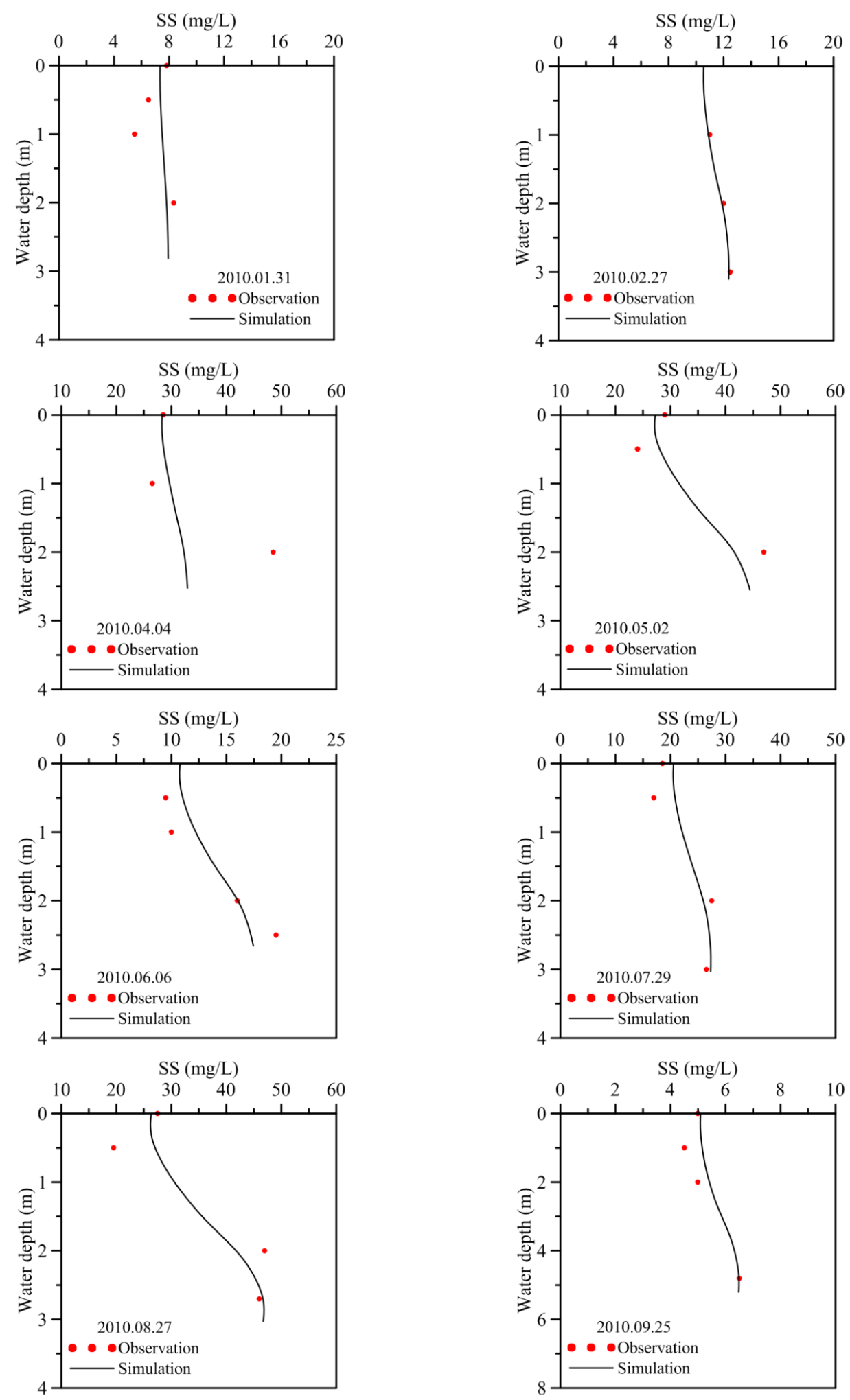

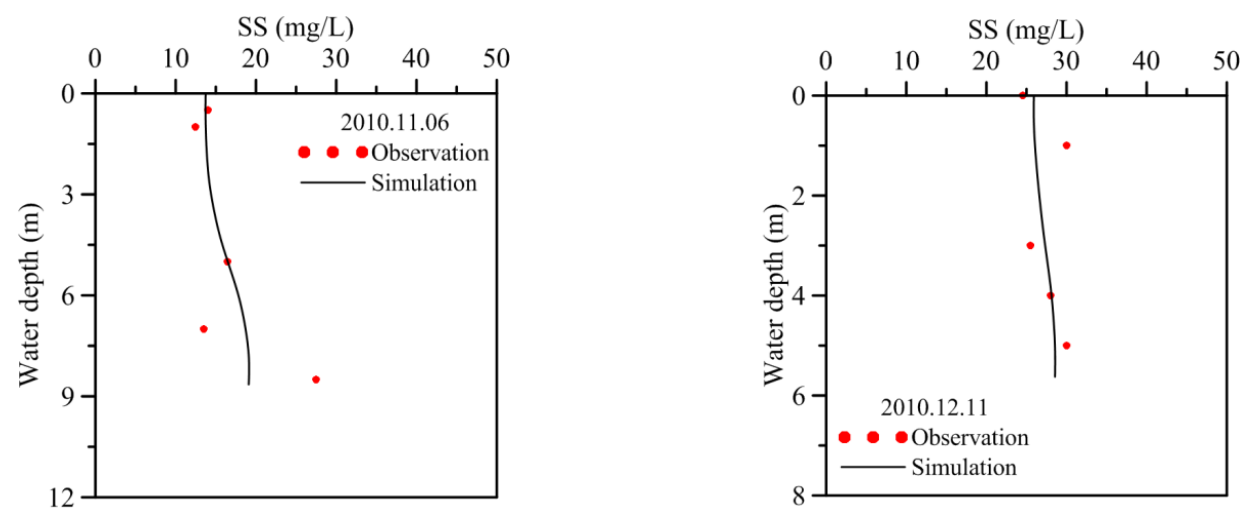

Figure 5. Comparison of vertical suspended-sediment profiles between model simulation and observation at the buoy station in 2010 .
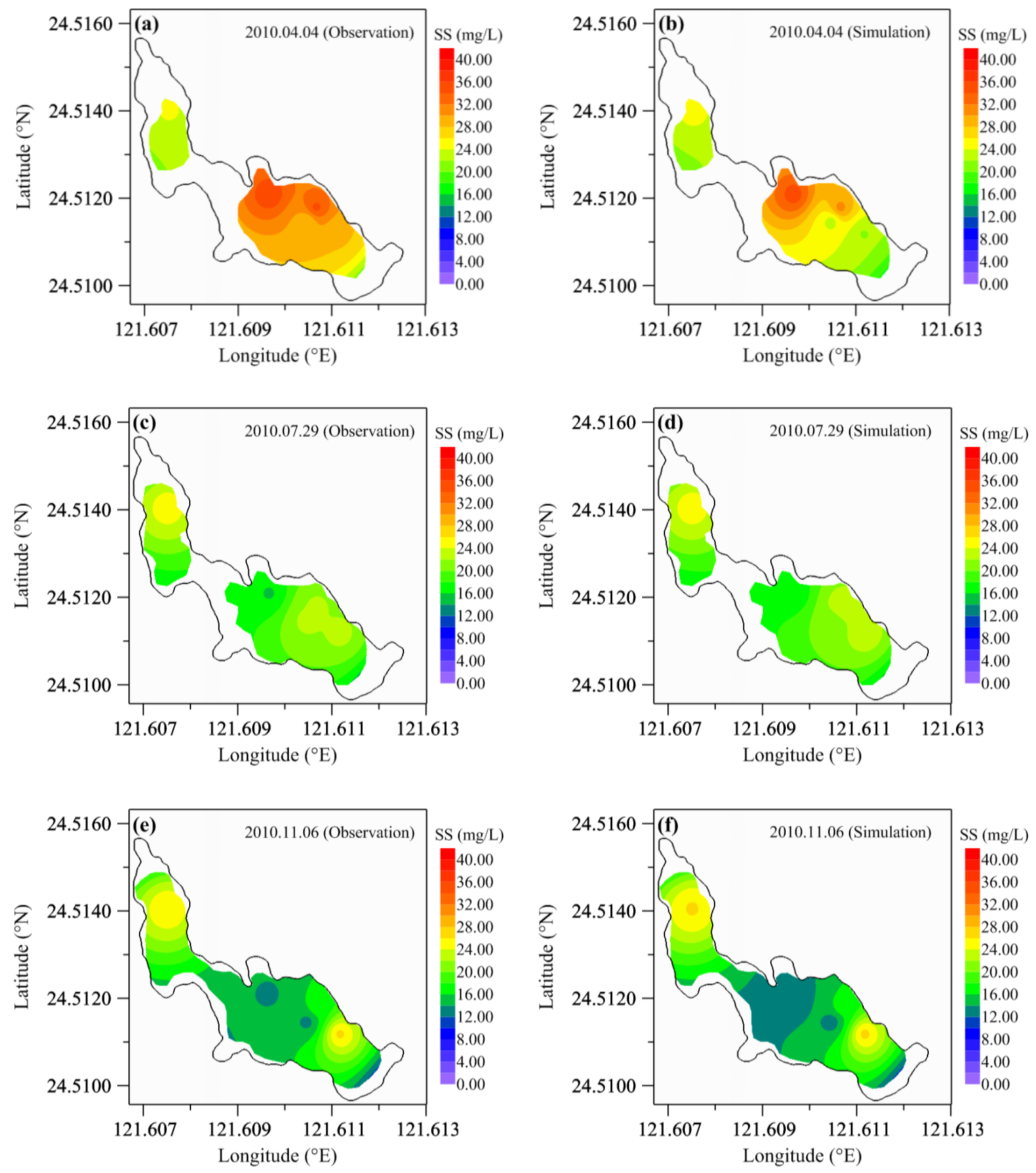

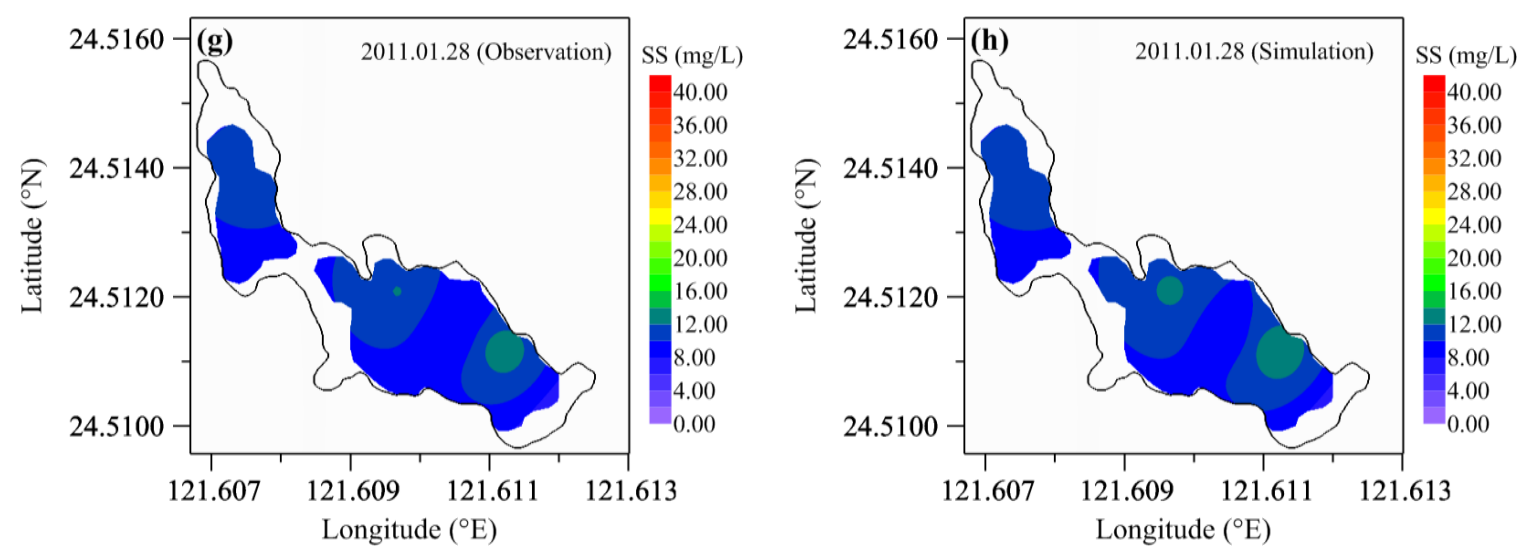

Figure 6. Comparison of spatial distributions of vertically averaged suspended-sediment concentration between model simula tion and observation on April 4, July 29, November 6, 2010 and January 28, 2011. Note that figures (a) and (b) show the observation and simulation on April 4, 2010. Figures (c) and (d) present the observation and simulation on July 29, 2010. Figures (e) and (f) are the observation and simulation on November 6, 2010. Figures (g) and (h) present the observation and simula tion on January 28, 2011.

\section{Model Investigations and Discussion}

\subsection{Model Sensitivity analysis}

Sensitivity analysis is the study of how the uncertainty in the output of a mathematical model can be apportioned to different sources of uncertainty in its inputs. Three-dimensional suspended-sediment transport models have been applied to examine the sensitivity of their models to alter the physical forcing [44-46]. In this study, model sensitivity analysis was implemented to explore the effects of settling velocity $\left(w_{s}\right)$, the critical stress for erosion $\left(\tau_{e c}\right)$, deposition $\left(\tau_{d c}\right)$, and the empirical erosion rate $(M)$ on the suspended-sediment concentration and to determine the most important factor that affects the suspended-sediment concentration in the TFL.

The original bases depend on the simulation of model validation from April 1, 2010 to April 30, 2010. The effects of these parameters on the suspended-sediment concentration were investigated with two alternative cases; one involves the value used in model validation plus $50 \%$ and the other involves the value minus $50 \%$. Figure 7 presents the model sensitivity results for the four parameters during April 2010. It indicates that the settling velocity would be the most important parameter affecting the suspended-sediment concentration in the TFL. Table 2 lists the model sensitivity results. It indicates that an increase in settling velocity results in a decrease in the suspended-sediment concentration. The maximum rates for decreasing and increasing suspended-sediment concentration are $43.85 \%$ and $179.15 \%$, respectively. The maximum rate $(M R)$ means that the maximum values were determined by the formula represented by

$$
M R=\frac{C_{\text {base }}-C_{\text {sens }}}{C_{\text {base }}} \times 100 \%
$$

where $C_{\text {base }}$ is the suspended-sediment concentration for the base runs shown in Figure 4 and $C_{\text {sens }}$ is the suspended-sediment concentration for the sensitivity run shown in Figure 7.

The most and least important factors to affect the suspended-sediment concentration are the settling velocity and the erosion rate, respectively, shown in Table 2 based on model sensitivity runs. Lee et al. [29] and Hawley et al. [20] used a one-dimensional (vertical) resuspended bed model and a two-dimensional (vertical and cross-shore) sediment transport model, respectively, to implement model sensitivity to identify the important resuspension parameters in Lake Michigan. They found that the settling velocity was crucial parameter in controlling the prediction of suspended-sediment concentration. Their simulated results of sensitivity analysis were similar with the current study with a three-dimensional suspended-sediment transport model. However, we 
further found that the erosion rate is the least important parameter in the suspended-sediment modeling.

Table 2. Results of model sensitivity run for four parameters .

\begin{tabular}{ccc}
\hline Parameter & Condition & $\begin{array}{c}\text { Maximum rate of suspended } \\
\text { sediment concentration }(\%)\end{array}$ \\
\hline Settling velocity $\left(w_{s}\right)$ & $w_{s}+50 \%$ & -43.85 \\
Criticalstress for & $w_{s}-50 \%$ & 179.15 \\
deposition $\left(\tau_{d c}\right)$ & $\tau_{d c}+50 \%$ & -24.31 \\
Criticalstress for e rosion & $\tau_{d c}-50 \%$ & 90.27 \\
$\left(\tau_{e c}\right)$ & $\tau_{e c}+50 \%$ & -0.49 \\
Erosion rate $(M)$ & $\tau_{e c}-50 \%$ & 2.80 \\
& $M+50 \%$ & 0.33 \\
\hline
\end{tabular}

Minus and plus represent decreasing and increasing suspended sediment concentrations, respectively.

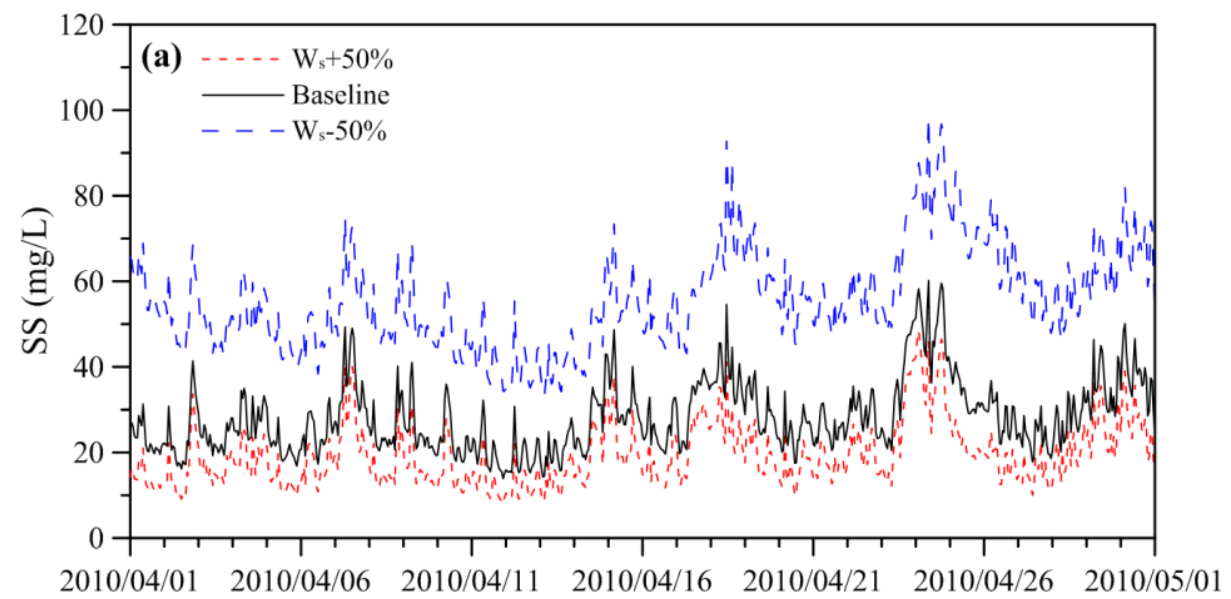

Time (year/month/day)

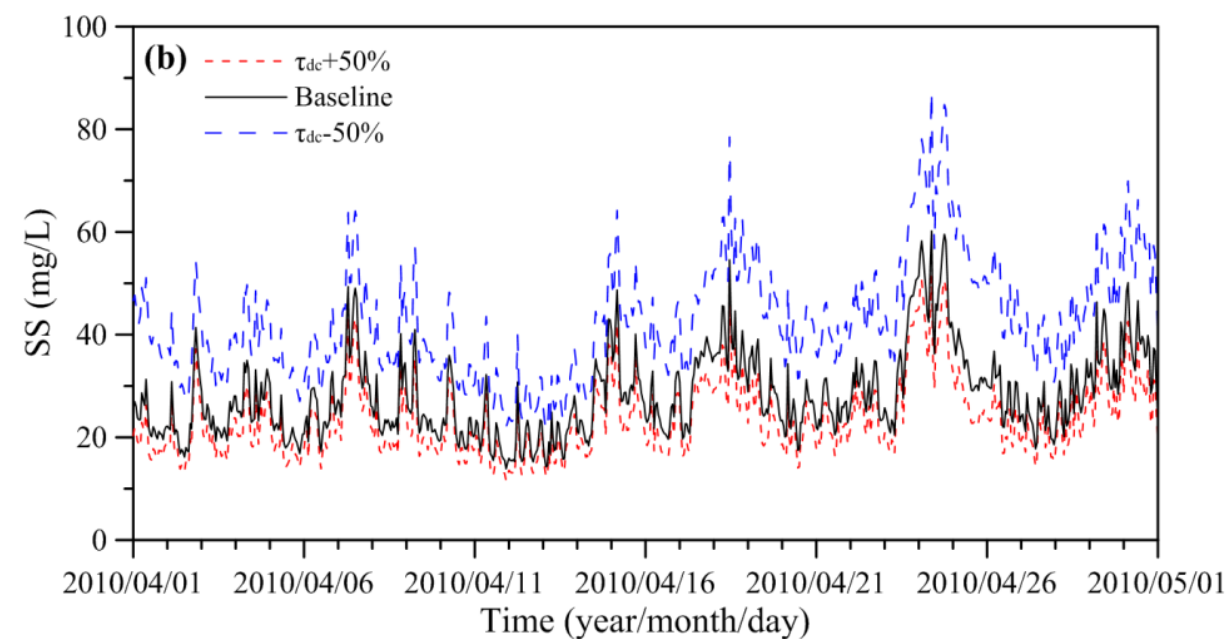



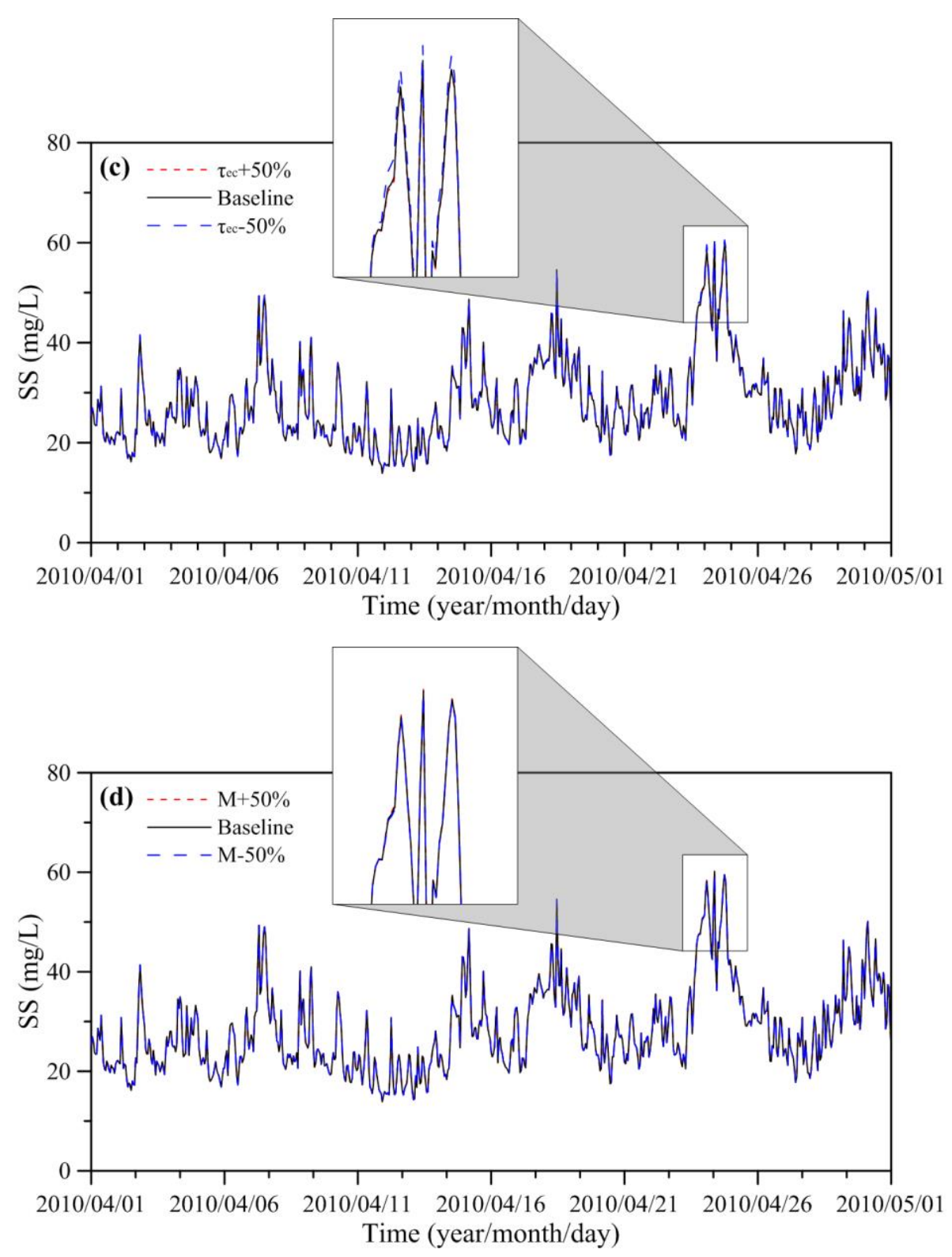

Figure 7. Model sensitivity for the (a) settling velocity $\left(w_{s}\right)$, (b) critical stress for deposition $\left(\tau_{d c}\right)$,

(c) critical stress for e rosion $\left(\tau_{e c}\right)$, and e rosion rate constant $(M)$.

\subsection{Influence of wind stress on current and suspended sediment}

The flows, surface waves, and sediment resuspension in the shallow lakes are significantly driven by wind forcing [47-49]. Podsetchine and Huttula [50] addressed the correlation and time lag of wind direction/speed to resuspended sediment in Lake Karhijärvi, Finland. Jin and Ji [51] applied a three-dimensional model to investigate the effects of wind velocity and fetch and wind persistence on suspended-sediment concentrations in Lake Okeechobee. The mean circulation in the TFL would be one of the important factors to affect the transport and distribution of suspended sediment. To investigate how the suspended sediment could be transported and distributed in the YYL, different $w$ ind speeds and directions including northeast wind: $2.23 \mathrm{~m} / \mathrm{s}$ (baseline), northeast wind: $9.39 \mathrm{~m} / \mathrm{s}$, northwest wind: $9.39 \mathrm{~m} / \mathrm{s}$, and southwest wind: $9.39 \mathrm{~m} / \mathrm{s}$ were used to drive the model simulation to yield mean circulation and suspended-sediment distribution. The wind speed and direction of $2.23 \mathrm{~m} / \mathrm{s}$ from the northeast in November 2010 were selected as baseline. The maximum wind speed is $9.39 \mathrm{~m} / \mathrm{s}$ during the model validation period and prevailing wind 
directions are northeast, northwest, and southwest adopted for model simulations to compare with the baseline condition.

The mean currents at the top and bottom layers for the baseline condition and for different wind speeds and directions, respectively, are shown in Figure 8 and Figure 9. The obvious anticyclonic circular gyre appears at the top layer for the baseline (Figure 8a), while the cyclonic circular gyre is seen at the top layer for the southwest wind (Figure 8d). Basically, the direction of the mean current at the top layer follows the wind direction. A strong wind results in high mean current at top layer. The bottom currents are smaller than the surface currents. The mean surface currents are between 0.018 and $33.0 \mathrm{~cm} / \mathrm{s}$, while the mean bottom currents are betw een 0.01 and 31.1 $\mathrm{cm} / \mathrm{s}$.

Figures 10 and 11 show the distributions of suspended-sediment concentration at the top and bottom layers, respectively, for the baseline condition and for different wind speeds and directions. Both figures indicate that the distributions of suspended-sediment concentration are obviously different depending on the wind speed and direction. A strong wind produces high suspended-sediment concentrations in the surface and bottom layers. The highest concentration appears near the buoy station, while the lowest concentration appears at the outlet. The mean surface concentrations are between 19.0 and $489.7 \mathrm{mg} / \mathrm{L}$, while the mean bottom concentrations are between 19.4 and $491.9 \mathrm{mg} / \mathrm{L}$ for a wind speed of $9.39 \mathrm{~m} / \mathrm{s}$. We found that the spatial distribution of the suspended-sediment concentration was subject to wind speed. Figure 12 illustrates the simulated results of the vertical suspended-sediment profile at the buoy station under conditions of different wind speeds and directions. It shows that the suspended-sediment concentrations in the vertical direction are homogeneous under conditions of a northeast wind, northwest wind, and southwest wind at $9.39 \mathrm{~m} / \mathrm{s}$, while stratification occurred with a northeast wind at $2.23 \mathrm{~m} / \mathrm{s}$. The different wind speeds and directions also produced different patterns in the vertical suspended-sediment concentration. The northwest wind at $9.39 \mathrm{~m} / \mathrm{s}$ produces the highest suspended-sediment concentration at the buoy station (Figure 12c). It implies that the water quality conditions in the lake may be affected by the wind stress. Jin and Ji [51] documented that the effects of wind-induced current and wind-induced resuspension on suspended-sediment transport were important factors affecting the suspended-sediment concentration in Lake Okeechobee. Cozar et al. [52] presented empirical correlations between turbidity and wind speed based on the field measurements. They yielded a formula and used the wind speed and water depth to calculate the suspended-sediment concentration. It meant that strength of wind speed was high correlation with the suspended-sediment concentration. In the present study, we also found that wind stresses have significantly influence on the mean circulation and suspended-sediment transport and distribution in a shallow lake.
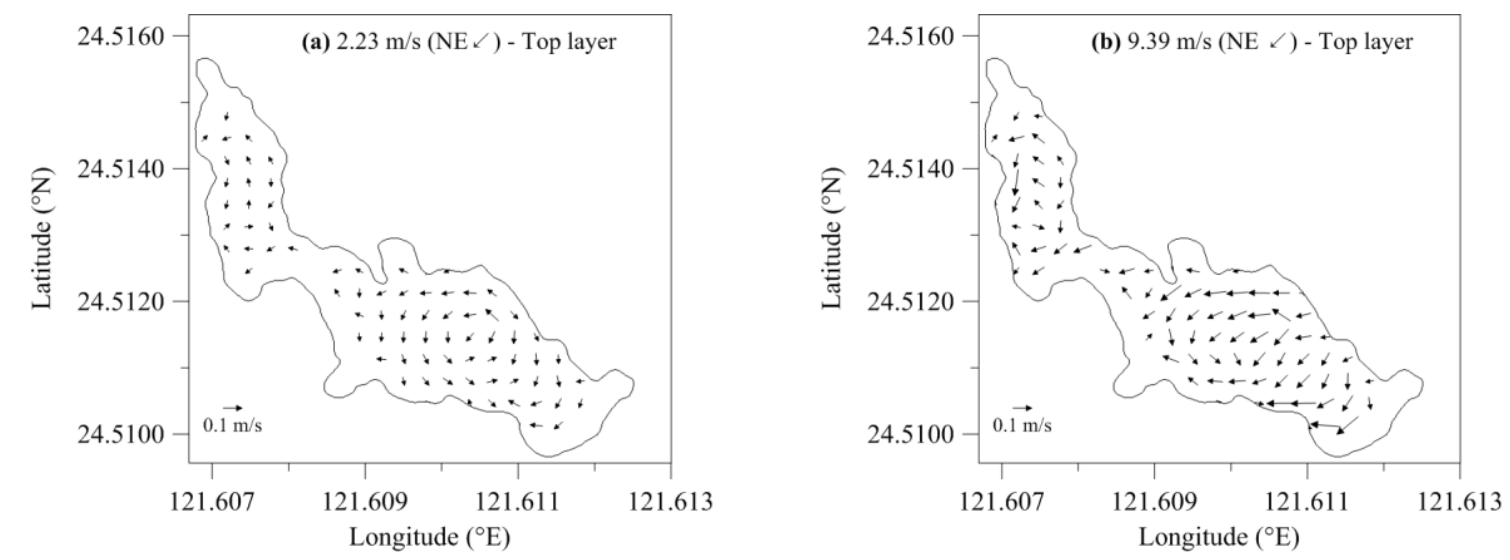

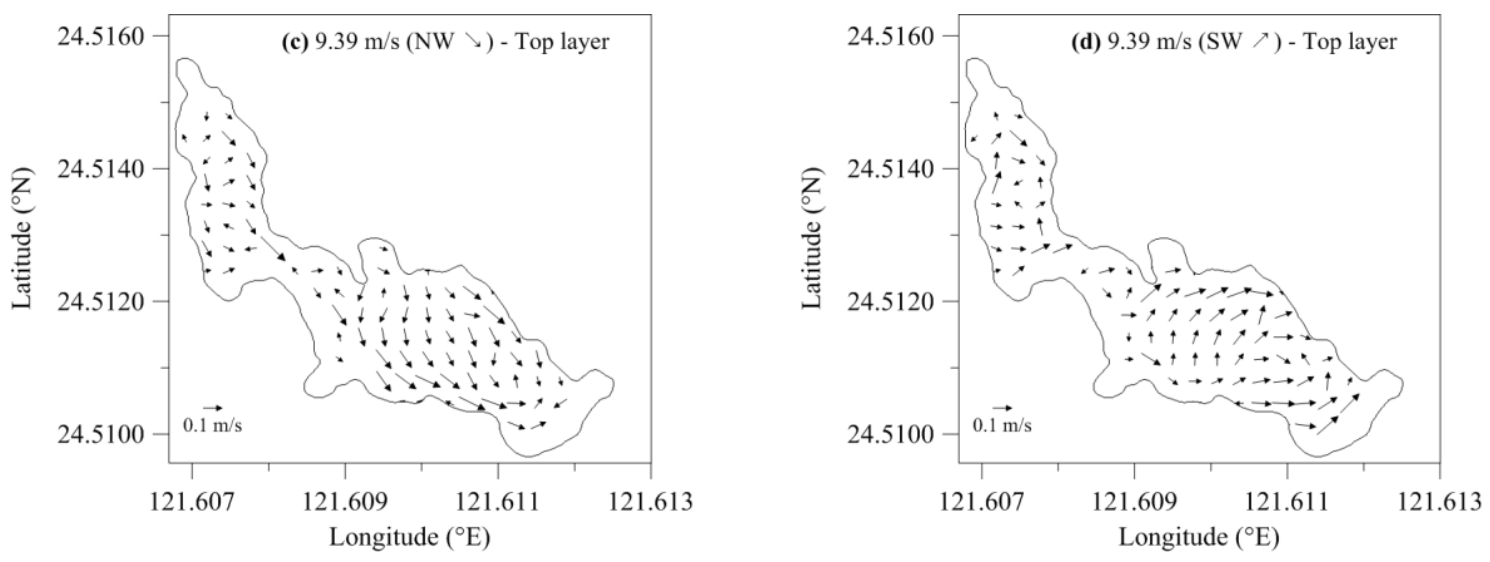

Figure 8. Mean circulation at the top layer for different wind speeds and directions (a) northeast wind: $2.23 \mathrm{~m} / \mathrm{s}$, (b) northeast wind: $9.39 \mathrm{~m} / \mathrm{s}$, (c) northwest wind: $9.39 \mathrm{~m} / \mathrm{s}$, and (d) southwest wind: $9.39 \mathrm{~m} / \mathrm{s}$.
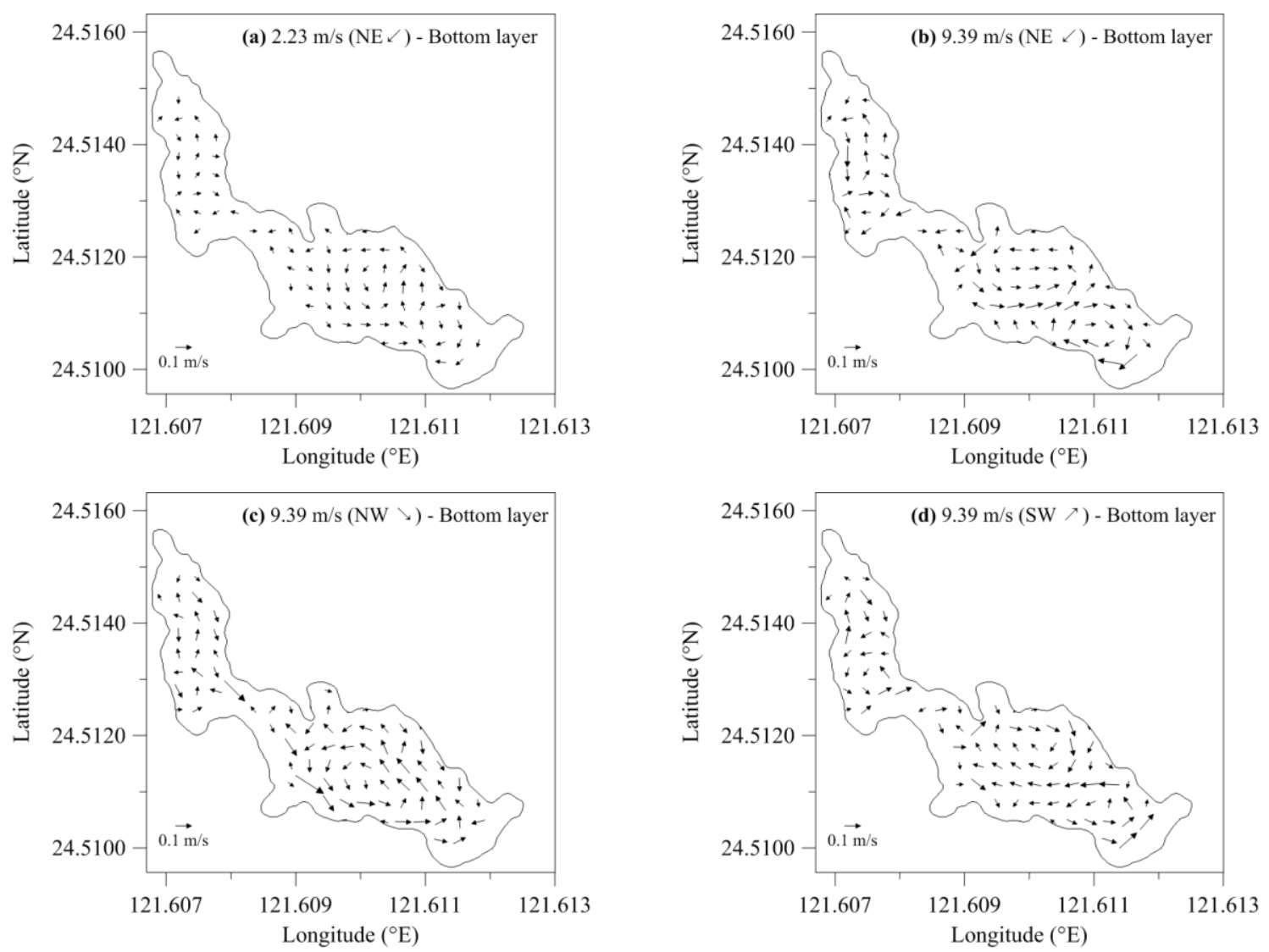

Figure 9. Mean circulation at the bottom layer for different wind speeds and directions (a) northeast wind: $2.23 \mathrm{~m} / \mathrm{s}$, (b) northeast wind: $9.39 \mathrm{~m} / \mathrm{s}$, (c) northwest wind: $9.39 \mathrm{~m} / \mathrm{s}$, and (d) southwest wind: $9.39 \mathrm{~m} / \mathrm{s}$. 

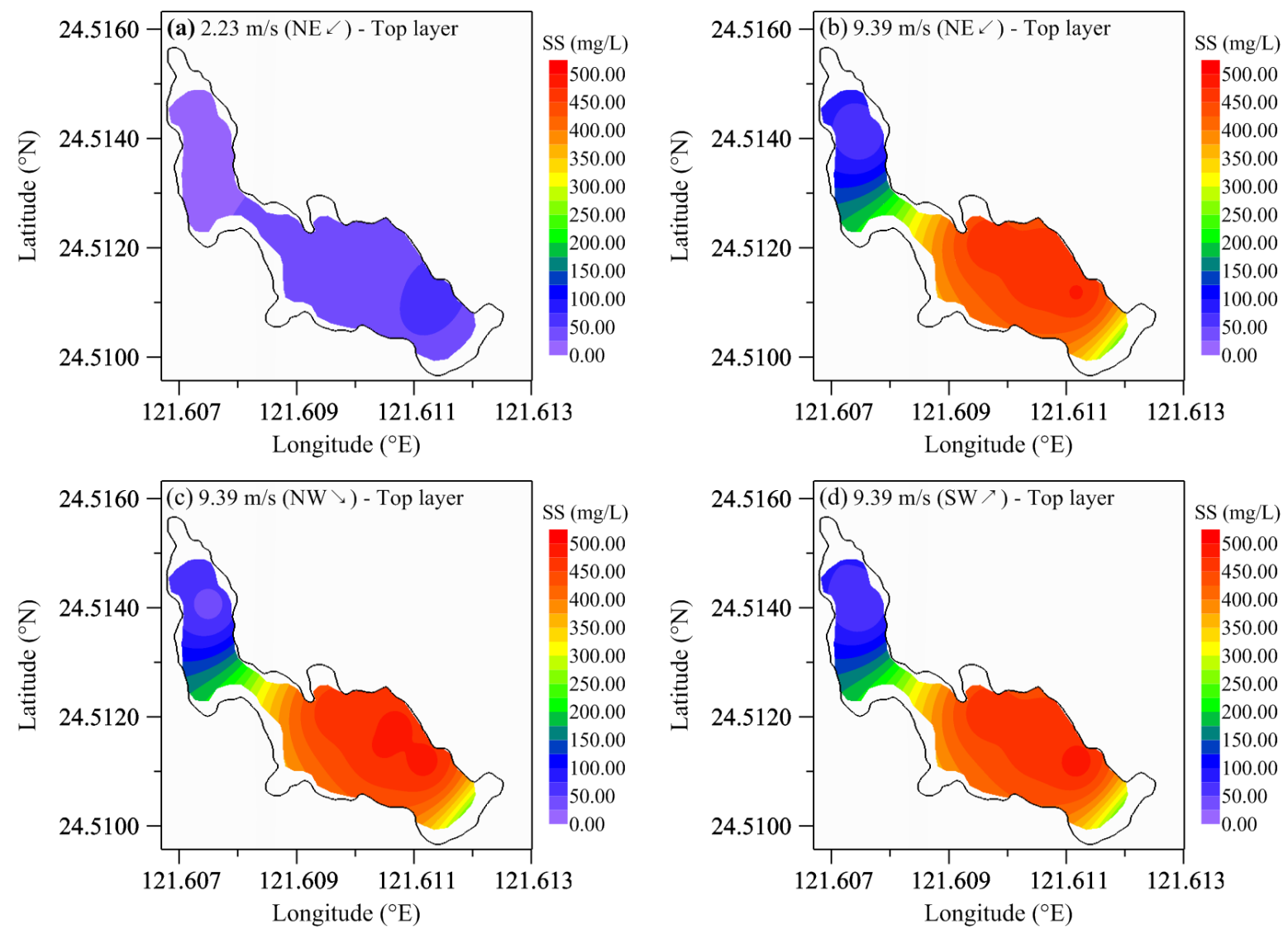

Figure 10. The distribution of mean sus pended-sediment concentration in the top layer for different wind speeds and directions (a) northeast wind: $2.23 \mathrm{~m} / \mathrm{s}$, (b) northeast wind: $9.39 \mathrm{~m} / \mathrm{s}$, (c) northwest wind: $9.39 \mathrm{~m} / \mathrm{s}$, and (d) southwe st wind: $9.39 \mathrm{~m} / \mathrm{s}$.
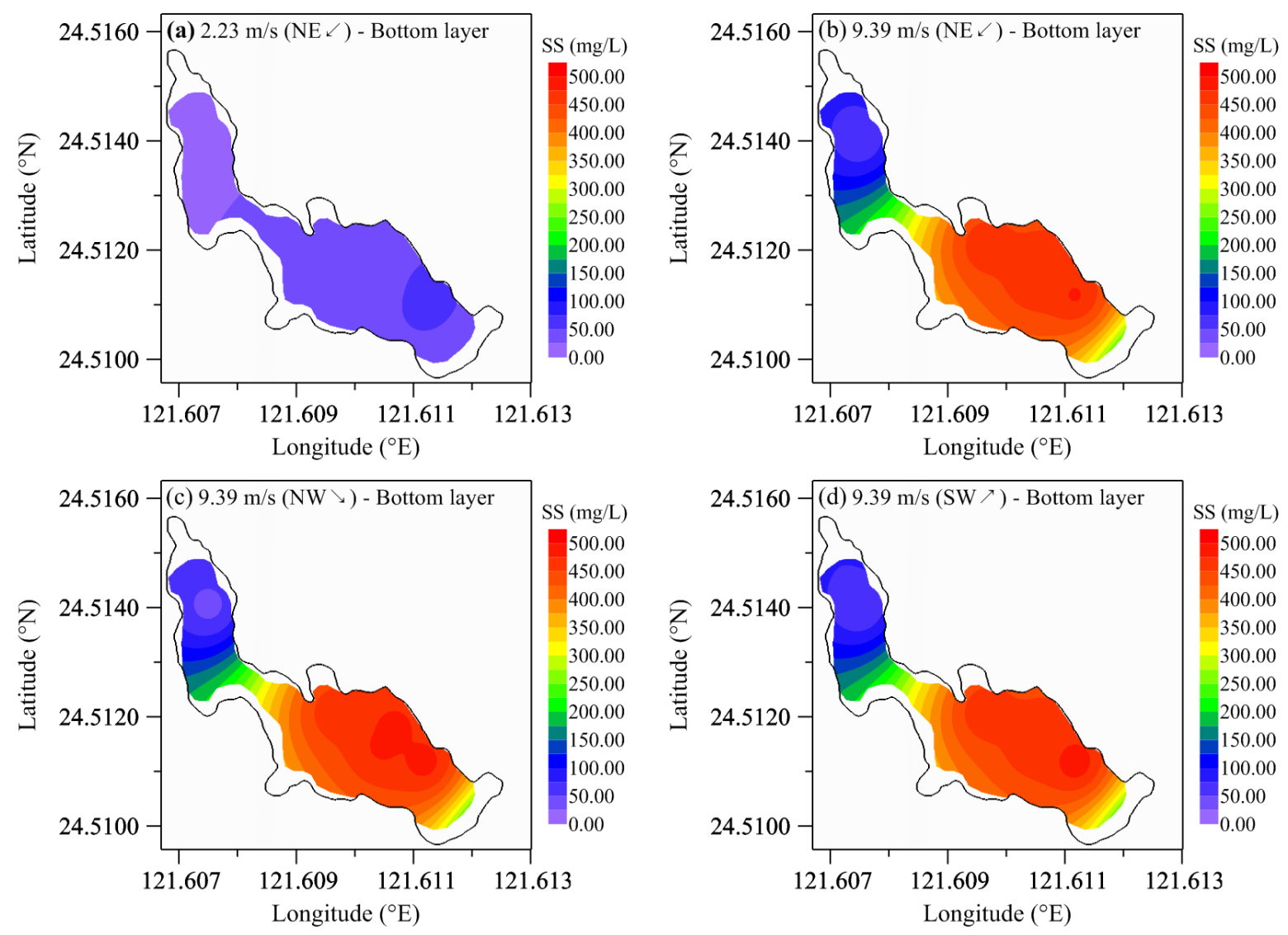
Figure 11. The distribution of mean suspended-sediment concentration at the bottom layer for different wind speeds and directions (a) northeast wind: $2.23 \mathrm{~m} / \mathrm{s}$, (b) northeast wind: $9.39 \mathrm{~m} / \mathrm{s}$, (c) northwest wind: $9.39 \mathrm{~m} / \mathrm{s}$, and (d) southwe st wind: $9.39 \mathrm{~m} / \mathrm{s}$.
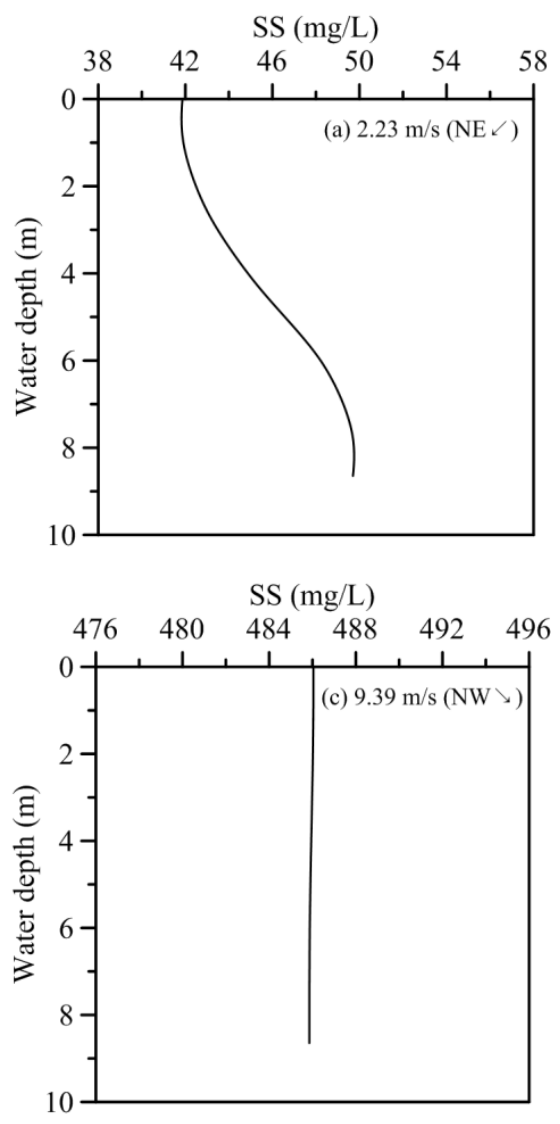
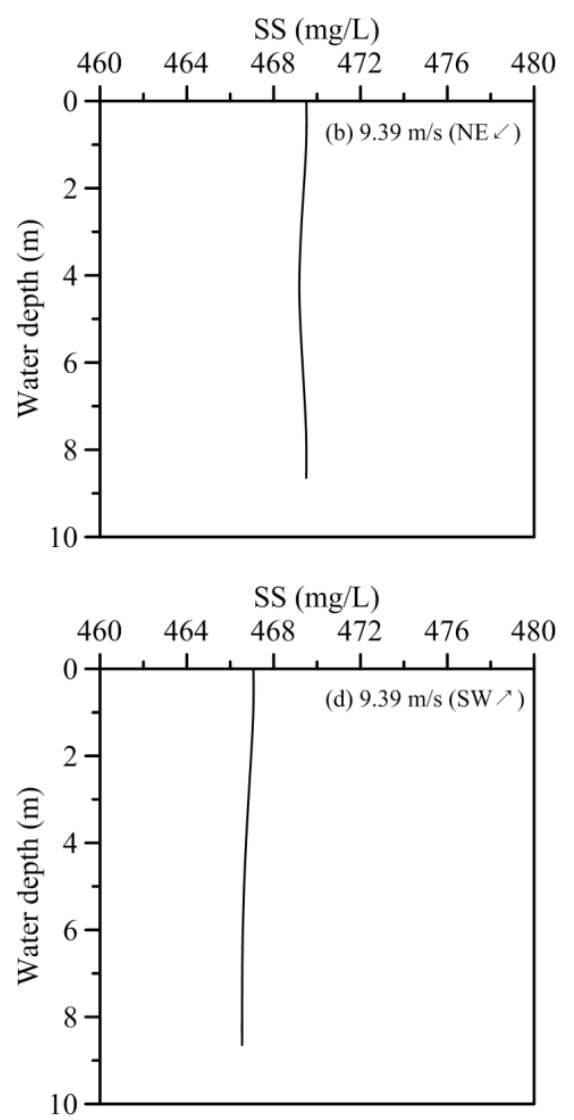

Figure 12. Vertical suspended-sediment profiles at the buoy station under different wind speeds and directions (a) northeast wind: $2.23 \mathrm{~m} / \mathrm{s}$, (b) northeast wind: $9.39 \mathrm{~m} / \mathrm{s}$, (c) northwest wind: 9.39 $\mathrm{m} / \mathrm{s}$, and (d) southwest wind: $9.39 \mathrm{~m} / \mathrm{s}$.

\section{Conclusions}

A three-dimensional hydrodynamic and suspended-sediment transport model $\mathrm{w}$ as developed and applied to the Tsuei-Feng Lake in the north-central region of Taiw an. The model was validated with observed water level and suspended-sediment concentrations in 2009, 2010, and 2011. The predicted results quantitatively agreed with measured data in the lake.

The validated model was applied to explore the crucial factor that most affects the suspended-sediment distribution in the TFL. Model sensitivity analysis indicates that the settling velocity is the most important parameter affecting the suspended-sediment concentration and the erosion rate is the least important parameter in the suspended-sediment transport modeling. Therefore, this parameter (i.e. settling velocity) should be carefully adjusted when the model is used for the model validation procedure. The model was also used to probe the mean current and suspended-sediment distribution in the TFL. Wind speed and direction are the dominant factors driving the current patterns and affecting the suspended-sediment concentration. The obvious anticyclonic and cyclonic circular gyres appear in the lake based on the wind stress. The distributions of suspended-sediment concentration are clearly different depending on the wind speed and direction. Strong winds result in high mean currents and suspended-sediment concentrations in the top and bottom layers due to the effect of resuspension in a shallow lake.

Ackno wledgments: This research was founded by the Academia Sinica, Taiwan (No. AS-103-TP-B15) and the Ministry of Science and Technology, Taiwan (MOST 105-2625-M-865-002). The financial support is greatly a ppre ciated. We also thank to Mr. Wei-Bo Chen for assistance in model modification. 
Author Contributions: Wen-Cheng Liu and Chih-Yu Chiu supervised the progress of the MOST and Academia Sinica projects and served as the general editors. Hong-Ming Liu performed the data collection, model establishment, and model simulations and discussed the results with Wen-Cheng Liu and Chih-Yu Chiu. All authors read and approved the final manuscript.

Conflicts of Interest: The authors decla re no conflict of interest.

\section{References}

1. Chao, X.; Jia, Y.; Shields, Jr. F.D.; Wang, S.S.Y.; Cooper, C. M. Numerical modeling of water quality and sediment related processes. Ecol. Model. 2007, 201, 385-297.

2. Chao, X.; Jia, Y.; Shields, Jr. F.D.; Wang, S.S.Y.; Cooper, C.M. Three-dimensional numerical modeling of cohesive sediment transport and wind wave impact in a shallow oxbow lake. Adv. Water Resour. 2008, 31, 1004-1014.

3. Chalov, S.R.; Jarsjo, J.; Kasimov, N.S.; Romanchenko, A.O.; Pietron, J.; Thorslund, J.; Promakhova, E.V. Spatio-temporal variation of sediment transport in the Selenga River Basin, Mongolia and Russia. Environ. Earth Sci. 2015, 73, 663-680.

4. Horne, A.J.; Goldman, C.R. Limnology. McGraw-Hill Higher Education. 1994.

5. DiToro, D.M. Sediment flux modeling. Wiley \& Sons, Inc, 2001.

6. Ji, Z.G.; Hamrick, J.H.; Pagenkopf, J. Sediment and metals in shallow river. J. Environ. Eng. ASCE 2002, 128, 105-119.

7. Gbah, M.B.; Rao, Y.R.; Murthy, R. Tuebulent exchange characteristics in the hypolimnion layer of Lake Ontario. Nordic Hydrol. 2001, 32, 13-28.

8. Partheniades, E. Erosion and de position of cohe sive soils. J. Hydraul. Div. ASCE 1965, 91, 105-139.

9. Krone, R.B. Flume studies on the transport of sediment in estuarine shoaling processes. Hydraulic Enginee ring Laboratory, Berkeley, University of Ca lifornia, 1962.

10. Mehta, A.J.; Partheniades, E. An investigation of the depositional properties of flocculated fine sediment. J. Hydraul. Res. 1975, 13, 361-381.

11. Thorn, M.F.C. Physical processes of siltation in tidal channels. In: Proceedings of Hydraulic Modelling Applied to Maritime Engineering Problems, London, ICE, 47-55, 1981.

12. Matty, J.M.; Anderson, J.B.; Dunbar, R.B. Suspended sediment transport, sedimentation, and resuspension in Lake Houston, Taxes: Implications for water quality. Environ. Geol. 1987, 10, 175-186.

13. Burban, P.Y.; Xu, Y.J.; Mcnell, J.; Lick, W. Settling speeds of flocs in fresh water and sea water. J. Geophys. Res. 1990, 95(C10), 18213-18220.

14. Ziegler, C.K.; Nisbet, B.S. Long-term simulation of fine-grained sediment transport in large reservoir. J. Hydraul. Eng. ASCE 1995, 121, 773-781.

15. Li, Y.; Mehta, A.J. Assessment of hindered settling of fluid mudlike suspensions. J. Hydraul. Eng. ASCE 1998, 124, 176-178.

16. Houwing, E.R.; Rijn, L.C. In situ e rosion flume (ISEF): determination of bed-shear stress and erosion of a kaolinite bed. J. Sea Res. 1998, 39, 243-253.

17. Clarke, G.K.C.; Bush, A.B.G.; Bush, J.W.M. Freshwater discharge, sediment transport, and modeled climate impacts on the final discharge of glacial Lake Agassiz. J. Climate, 2009, 22, 2161-2180.

18. Chung, E.G.; Bombardelli, F.A.; Schladow, S.G. Modeling linkages between sediment resus pens ion and water quality in a shallow, eutrophic, wind-exposed lake. Ecol. Model. 2009, 220, 1251-1265.

19. Filistovic, V.; Maceika, E.; Tarasiuk, N.; Lukisence, B.; Konstantinova, M.; Buivydas, S.; Koviazine, E.; Puzas, A. Model of nonequilibrium multiphase contaminant transport in lake water-sediment system. Water Air Soil Poll. 2015, 226, 202.

20. Hawley, N.; Harris, C.K.; Lesht, B.M.; Clites, A.H. Sensitivity of a sediment transport model for Lake Michigan. J. Great Lakes Res. 2009, 35, 560-576.

21. Zouabi-Aloui, B.; Gueddari, M. Two-dimensional modelling of hydrodynamics and water quality of a stratified dam reservoir in the southern side of the Mediterranean Sea. Environ. Earth Sci. 2014, 72, 3037-3051.

22. Lee, C.; Schwab, D.J.; Beletsky, D.; Stroud, J.; Lesht, B. Numerical modeling of mixed sediment resuspension, transport, and deposition during the March 1988 episodic events in southern Lake Michigan. J. Geophys. Res. 2007, 112, C02018.

23. Stroud, J.R.; Lesht, B.M.; Schwab, D.J.; Beletsky, D.; Stein, M.L. Assimilation of satellite imagines into a 
se diment transport of Lake Michigan. Water Resour. Res. 2009, 45, W02419.

24. Faghihirad, S.; Lin, B.; Falconer, R.A. Application of a 3D layer integrated numerical model of flow and sediment transport processes to a reservoir. Water, 2015, 7, 5239-5257.

25. Wang, H.; Zhang, Z.Z.; Song, D.P.; Zhou, Y.Y.; Liu, X.D. Water and sediment transport mechanisms in a larger liver-connected lake. Water Environ. J. 2015, 29, 391-401.

26. Zhang, P.; Chen, X.L.; Lu, J.Z.; Zhang, W. Assimilation of remote sensing observations into a sediment transport model of China's large freshwater lake:s patial and temporal effects. Environm. Sci. Pollut. Res. 2015, 22, 18779-18792.

27. Lou. J.; Schwab, D.J.; Beletsky, D.; Hawley, N. A model of se diment resuspension and transport dynamics in southern Lake Michigan. J. Geophys. Res. 2000, 105(C3), 6591-6610.

28. Cardenas, M.P.; Schwab, D.J.; Ea die, B.J.; Hawley, N.; Lesht, B.M. Sediment trans port model validation in Lake Michigan. J. Great Lakes Res. 2005, 31, 373-385.

29. Lee, C.; Schwab, D.J.; Hawley, N. Sensitivity analys is of sediment resuspension parameters in coastal area of southern Lake Michigan. J. Geophys. Res. 2005, 110, C03004.

30. Lv, C.; Zhang, F.; Liu, Z.; Hao, S.; Wu, Z. Three-dimensional numerical simulation of sediment trans port in Lake Tai based on EFDC model. J. Food Agricu. Environ. 2013, 11, 1343-1348.

31. Wang, C.; Shen, C.; Wang, P.F.; Qian, J.; Hou, J.; Liu, J.J. Modeling of sediment and heavy metal transport in Taihu Lake, China. J. Hydrodyn. 2013, 25, 397-387.

32. Liu, W.C.; Chan, W.T.; Tsai, D.W. Three-dimensional modeling of suspended sediment transport in a subalpine lake. Environ. Earth Sci. 2006, 75:173.

33. Sanford, L.P. New sedimentation, resuspension and burial. Limnol. Oceanogr. 1992, 37, 1164-1178.

34. Cheng, W.Y. Using water quality variables to estiablish light attenuation model in subtropic subaline Yuan-Yang Lake and Tsuei-Feng Lake. Mater Thesis of Deperamtn of Civil and Disaster Prevention Engineering, NationalUnited University, Taiwan, 2010.

35. Zhang, Y.L.; Baptista, A.M. SELFE: A semi-implicit Eulerian-Lagrangian finite element model for cross-scale ocean circula tion. Ocean Model. 2008, 21, 71-96.

36. Umlauf, L.; Buchard, H. A generic length-scale equation for geophysical turbulence models. J. Mar. Res. 2003, 61, 235-265.

37. Lin, J.; Kuo, A.Y. A model study of turbidity maximum in the York River estuary, Virginia. Estuaries 2003, $26,1269-1280$.

38. Thomann, R.V.; Mueller, J.A. Principles of surface water quality modeling and control. Harper Collins Publishers, Inc., New York, 1987.

39. Liu, W.C. Modeling the influence of settling velocity on cohesive sediment transport in Tanshui River estuary. Environ. Geol. 2005, 47, 535-546.

40. Young, S. M.; Ishiga, H. Environmental change of the fluvialestuary system in relation to Arase Dam removal of the Yatsushiro tidal flat, SW Kyushu, Japan. Environ. Earth Sci. 2014, 72, 2301-2314.

41. Chen, W.B.; Liu, W.C.; Hsu, M.H.; Hwang, C.C. Modelling investiagtion of susppended sediment in a tidal estuary using a three-dimensional model. Appl. Math. Model. 2015, 39, 2570-2586.

42. Duy Vinh, V.; Ouillon, S.; Van Thao, N.; Tien, N.N. Numerical simulaitons of suspended sediment dynamics due to seasonal forcing in the Mekong coastal area. Water, 2016, 8, 255.

43. APHA. Standard methods for the examination of water and wastewater. 19th ed. American Public Health Association, Washington, DC., USA, 1995.

44. Stanev, E.V.; Brink-Spalink, G.; Wolff, J.O. Sediment dynamics in tidally dominated environments controlled by transport and turbulence: a case study for the East Frisian Wadden Sea. J. Geophys. Res. 2007, 112, C04018.

45. Wang, X.H.; Pinardi, N.; Malacic, V. Sediment transport and resuspension due to combined motion of wave and current in the northern Adriatic Sea during a Bora event in January 2001: a numerical study. Cont. Shelf Res. 2007, 27, 613-633.

46. Warner, J.C.; Butman, B.; Dalyander, P.S. Storm-driven sediment transport in Massachusetts Bay. Cont. Shelf Res. 2008, 28, 257-282.

47. Kjaran, S.P.; Holm, S.L.; Myer, E.M. Lake circulation and sediment transport in Lake Myvatn. Aquat. Ecol., 2004, 38, 145-162.

48. Kimura, N.; Liu, W.C.; Chiu, C.Y.; Kratz, T.K. Assessing the effects of severe rainstorm-induced mixing on a subtropical, subalpine lake. Environ. Monit. Assess. 2014, 186, 3091-3114. 
49. Scheon, J.; Stretch. D.; Tirok, K. Wind-driven circulation patterns in shallow estuarine lake: St Lucia, South Africa. Estuar. Coast. Shelf Sci. 2014. 146, 49-59.

50. Podsetchine, V.; Huttula, T. Modeling sedimentation and resuspension in lake. Water Pollut. Res. J. Canada 1994, 29, 309-342.

51. Jin, K.R.; Ji, Z.G. Case study: modeling of se diment transport and wind-wave impact in Lake Okeechobee. J. Hydraul Eng. ASCE 2004, 130, 1055-1067.

52. Cozar, A.; Galvez, J.A.; Hull, A.; Garcia, C.M.; Loiselle, S.A. Sediment resuspension by wind in a shallow lake of Esteros delIbera (Argentina): a model based on trubidimetry. Ecol. Model. 2005, 186, 63-76. 